\section{BMJ Open \\ Respiratory \\ Research}

\title{
Childhood adversity and asthma prevalence: evidence from 10 US states (2009-2011)
}

\author{
Nandita Bhan, ${ }^{1}$ M Maria Glymour, ${ }^{2}$ Ichiro Kawachi, ${ }^{3}$ S V Subramanian ${ }^{3}$
}

To cite: Bhan N,

Glymour MM, Kawachi I, et al. Childhood adversity and asthma prevalence: evidence from 10 US states (20092011). BMJ Open Resp Res 2014:1:e000016.

doi:10.1136/bmjresp-2013000016

- Additional material is published online only. To view please visit the journal online (http://dx.doi.org/10. 1136/bmjresp-2013-000016)

Received 31 October 2013 Revised 4 February 2014 Accepted 6 February 2014

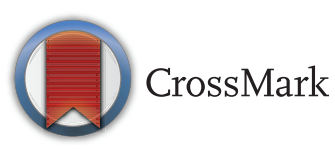

\footnotetext{
${ }^{1}$ South Asia Network for Chronic Diseases, Public Health Foundation of India, New Delhi, India

${ }^{2}$ Department of Epidemiology \& Biostatistics, UCSF School of Medicine, San Francisco, California, USA

${ }^{3}$ Department of Social \& Behavioral Sciences, Harvard School of Public Health,
} Boston, Massachusetts, USA

Correspondence to Professor S V Subramanian; svsubram@hsph.harvard.edu

\section{ABSTRACT}

Background: Existing evidence on stress and asthma prevalence has disproportionately focused on pregnancy and postpregnancy early life stressors, largely ignoring the role of childhood adversity as a risk factor. Childhood adversity (neglect, stressful living conditions and maltreatment) may influence asthma prevalence through mechanisms on the hypothalamic-pituitary axis.

Methods: Data from the Center for Disease Control's (CDC's) Behavioral Risk Factor Surveillance System (BRFSS) surveys were used to examine cross-sectional associations of adverse childhood experiences (ACE) with lifetime and current asthma prevalence. Information on childhood adversity was available from 84786 adult respondents in 10 US states. Poisson regression models (with robust $\mathrm{SE}$ ) were used to estimate prevalence ratios (PRs) relating overall ACE score and dimensions of exposure ACE to asthma prevalence, adjusting for socioeconomic status.

Results: Greater ACE was associated with a higher prevalence of asthma (adjusted $\mathrm{PR}_{\text {cat }} 4=1.78(95 \% \mathrm{Cl}$ 1.69 to 1.87 ), adjusted $\mathrm{PR}_{\text {cat } 1}=1.21(95 \% \mathrm{Cl} 1.16$ to 1.27)). Reported experiences of sexual abuse (adjusted $\mathrm{PR}=1.48^{*}$ (1.42 to 1.55$)$ ) and physical abuse (adjusted $P R=1.38^{*}$ (1.33 to 1.43)) were associated with a higher asthma prevalence. No clear socioeconomic gradient was noted, but those reporting lowest education and income levels reported high rates of asthma and adversity. Sensitivity analyses indicated that ACE exposures were interrelated.

Conclusions: Report of childhood adversity predicts asthma prevalence among US adults. Frameworks for asthma prevention need to recognise and integrate aspects related to childhood adversity. Further investigation into specific time periods of exposure would provide meaningful inferences for interventions.

\section{INTRODUCTION}

The majority of research linking stress with asthma has focused on pregnancy and postpregnancy early life stressors, with little investigation into childhood adversity and its long-term impacts. Three sets of epidemiological studies have dominated the discussion. First, studies examining in utero effects of

\section{Strengths and limitations of this study}

- Greater adversity in childhood associated with increased risk of current and lifetime asthma prevalence.

- Dimensions of adversity (parental discord, stressful living conditions, verbal, physical and sexual abuse) were, singularly and in combinations, associated with increased asthma risks.

- Lowest SES groups at higher risks of adversity, but unclear socioeconomic gradients.

stress during pregnancy and immediate postpregnancy risk factors have assessed evidence for programming of respiratory health. ${ }^{1-4}$ Second, studies have drawn associations between reported or measured parental stress as predictors of wheezing among children. ${ }^{5-7}$ Third, associations between mental distress and asthma have been examined. ${ }^{5-11}$

Assessing the role of childhood adversity investigates and relates to the research around physiological mechanisms for stress and asthma research. Evidence from stress biology finds links to asthma (along with bronchial hypersensitivity, eczema and wheezing) through immune and inflammatory responses, acting through the hypothalamic-pituitary axis. ${ }^{1}{ }^{12-14}$ For instance, extreme stress and emotional states such as trauma have been associated with asthma through immune dysregulation as well as nervous system hyper-responsiveness. The role of such mechanisms may be more pronounced in childhood compared to pregnancy and postpregnancy. Further, hormones and inflammation (eg, interleukin (IL)-4, IL-5 and IL-13) related to stress can lead to contractions of smooth muscle and excess of mucus production, heightening risks for asthma morbidity ${ }^{14}$ Hormonal mechanisms influencing weight gain and obesity have also been associated with stress and asthma. ${ }^{15} 16$

Research on childhood adversity may also address some limitations in the current 
epidemiological research on stress and asthma. Childhood adversity, often reported, examines the qualitative nature of experiencing stress in social interactions instead of focusing on stress biomarkers. In previous epidemiological studies, household or parental measures of stress were equated to the individual's own stress. This ignores the role of factors such as personality, resilience and the interactions between individual-social environments.

Childhood adversity has been operationalised by adverse childhood experiences (ACE), a multi-domain marker measuring diverse aspects of adversity including neglect, stressful living conditions, maltreatment and abuse. A number of studies have examined associations between ACE and health behaviours (including smoking, alcohol and drug initiation), suicide ideation and mental health outcomes. ${ }^{17-27}$ A handful of studies relating separate aspects of adversity to asthma outcomes have highlighted the potential for this relationship. For instance, a prospective follow-up of African-American women showed higher incidence rate ratios (IRRs) for physician-diagnosed asthma associated with any childhood abuse (IRR=1.24 (95\% CI 1.06 to 1.45 ) and any adolescent abuse $\left(\right.$ IRR $=1.10(95 \%$ CI 0.88 to 1.36$){ }^{28}$ Respondent's child protection agency history (a proxy for a stressful home environment or parental discord) was associated with higher elevated odds of lifetime asthma (adjusted $\mathrm{OR}=2.26,95 \%$ CI 1.33 to 3.83); the association did not hold, however, for self-reported measures for the same exposure. ${ }^{29}$ Hyland $e t a l^{30}$ showed that reported insults and physical punishment during childhood was associated with a higher likelihood of asthma (RR: 1.6).

In the context of these gaps, this study examined the relationships between overall ACE as well as independent ACE dimensions with asthma prevalence, using data from 10 US states between 2009 and 2011. We hypothesised positive relationships between adversity (measured through ACE) and asthma prevalence, even as relationships with markers of socioeconomic status (SES) may be variable for adversity and asthma.

\section{MATERIALS AND METHODS \\ Data and sample}

Behavioral Risk Factor Surveillance System (BRFSS) is a nationally representative annual telephone health survey designed and administered by the Center for Disease Control (CDC) that collects data on health risk behaviours, preventive health practices and access to healthcare across US states. ${ }^{31}$ As a repeated cross-sectional survey, it was designed to help in tracking preventive health goals and for highlighting emerging issues.

Information on self-reported physician-diagnosed asthma prevalence was available for 1384116 respondents across the USA between 2009 and 2011; however, information on childhood adversity measures was available for 84796 respondents (2009: 12 088, 2010: 24334 and 2011: 48 364). Hence, the total sample ' $n$ ' for this study was 84796 (men: 40.1\%, women: 59.9\%) from 10 US states, representing all geographic regions: Arkansas, District of Columbia (DC), Hawaii, Louisiana, Minnesota, Montana, Nevada, Vermont, Washington and Wisconsin.

\section{Variables}

The main outcomes analysed in the study were selfreported physician-diagnosed asthma prevalence among adults (measured by lifetime and current asthma). Respondents in the survey were asked: "(Ever told) by a doctor, nurse or other health professional that you had asthma" followed by "Do you still have asthma?". These outcomes have not been systematically tested for outcome reliability and validity. A review on self-reported asthma has estimated a mean sensitivity of $68 \%$ (range $48-100 \%$ ) and a mean specificity of $94 \%$ (range 78 $100 \%$ ), with an increase if physician-diagnosis was reported. ${ }^{32}$

The main exposure of interest was childhood adversity operationalised as an ACE score. The analysis used both overall ACE score (categorised by adversity type) and five separate dimensions of ACE. Eleven questions from a submodule administered in 10 states gathered data from respondents regarding ACE (details in online supplementary table S2). Five separate dimensions were considered and represented inter-related aspects of experience of stress before age 18 years (details discussed in online supplementary table S2). These included: (1) parental marital discord, (2) stressful living conditions, (3) experience of verbal abuse, (4) experience of physical abuse and (5) experience of sexual abuse. ACE questions used in the BRFSS have been tested previously for reliability. ${ }^{21}$ Weighted-к for individual questions and accumulated dimensions ranged from 0.52 to 0.86 with the reliability estimate for overall ACE being 0.64 (0.36 to 0.6). ${ }^{21}$ The interrelatedness of ACE dimensions has also been tested previously, with $81-98 \%$ of respondents reporting more than one dimension of ACE. ${ }^{33}$ The type of adversity measured by ACE was categorised into an exploratory gradient. The categories considered included: 'none' (category 0), 'parental marital discord or verbal abuse' (category 1), 'discord, verbal abuse and stressful living conditions' (category 2), 'discord, verbal abuse, stressful living conditions and physical abuse' (category 3) and 'discord, verbal abuse, stressful living conditions, physical and sexual abuse, and sexual abuse only' (category 4; see online supplementary table $\mathrm{S} 1$ ).

Other covariates in the analysis included respondent household income and education, age, sex, race, survey year and state of residence. Respondents did not provide data on parents, and hence their self-reported education and income were used as controls and proxies for lifetime SES. Household income was categorised into six categories (less than US $\$ 15000$, US $\$ 15000-35000$, US $\$ 35000-50000$, US\$50 000-75 000, >US\$75 000 and not 
reported or refused) and education was categorised as 'Less than high school', 'Finished high school', 'Some college' and 'College or more'. Respondent self-reports of race/ethnicity were categorised as Non-Hispanic White (NHW), Non-Hispanic Black (NHB), Hispanic and Other (including multiracial).

\section{Analysis}

The study estimated prevalence rates for lifetime and current asthma, along with dimensions of childhood adversity in the sample. Bivariate associations (along with $\chi^{2}$ tests) were estimated for asthma prevalence and ACE (overall and dimensions) with socioeconomic covariates of interest. Multivariable Poisson regression models with robust SE were used to estimate prevalence ratios (PRs) for asthma by ACE, adjusted for SES. PRs were preferred as risk ratio estimates over ORs due to the high prevalence of asthma in several categories. ${ }^{34} 35$ Regression models included unadjusted models (M1); models adjusted for age, sex, race and survey year (M2); models adjusted for age, sex, race, survey year and SES (M3) and models adjusted for age, sex, race, survey year, SES and state (M4). All analyses were conducted using STATAV.12.

\section{RESULTS}

\section{Prevalence rates for ACE and asthma}

Table 1 shows the differences in asthma prevalence (lifetime and current) by socioeconomic and demographic

Table 1 Sample characteristics and associations between asthma prevalence and socioeconomic and demographic variables

\begin{tabular}{|c|c|c|c|}
\hline & Sample (\%) & $\begin{array}{l}\text { Lifetime asthma } \\
\text { prevalence }^{\star}\end{array}$ & $\begin{array}{l}\text { Current asthma } \\
\text { prevalence }^{\star}\end{array}$ \\
\hline \multicolumn{4}{|l|}{ Sex } \\
\hline Male & $34003(40.1)$ & 10.72 & 6.83 \\
\hline Female & 50783 (59.9) & 14.84 & 11.07 \\
\hline \multicolumn{4}{|l|}{ Age } \\
\hline $18-24$ & 3133 (3.7) & 17.71 & 10.95 \\
\hline $25-44$ & $17750(20.94)$ & 14.79 & 10.009 \\
\hline $45-64$ & 36727 (43.32) & 13.19 & 9.48 \\
\hline$>65$ & 26524 (31.28) & 11.62 & 8.54 \\
\hline \multicolumn{4}{|l|}{ Income } \\
\hline$<$ US\$15 000 & 7092 (8.36) & 19.75 & 15.62 \\
\hline US\$15 000-US\$35 000 & $22322(26.33)$ & 14.29 & 10.62 \\
\hline US\$35 000-US\$50 000 & 11864 (13.99) & 12.46 & 8.63 \\
\hline US\$50 000-US\$75 000 & 12702 (14.98) & 11.99 & 8.12 \\
\hline >US\$75000 & $20832(24.57)$ & 11.05 & 7.10 \\
\hline \multicolumn{4}{|l|}{ Education } \\
\hline$<$ High school & $5790(6.83)$ & 16.7 & 13.26 \\
\hline Finished high school & $23639(27.88)$ & 12.58 & 9.41 \\
\hline Some college & 23480 (27.69) & 13.79 & 9.67 \\
\hline College+ & $31742(37.44)$ & 12.56 & 8.41 \\
\hline \multicolumn{4}{|l|}{ Race/ethnicity } \\
\hline Non-Hispanic White & 68485 (80.77) & 12.49 & 8.97 \\
\hline Non-Hispanic Black & $5351(6.31)$ & 15.7 & 11.67 \\
\hline Hispanic & $2561(3.02)$ & 13.67 & 8.81 \\
\hline Others (including multiracial) & 7523 (8.87) & 17.4 & 11.57 \\
\hline \multicolumn{4}{|l|}{ Survey year } \\
\hline 2009 & $12088(14.26)$ & 11.01 & 7.47 \\
\hline 2010 & 24334 (28.7) & 15.1 & 10.17 \\
\hline 2011 & $48364(57.04$ & 12.77 & 9.45 \\
\hline \multicolumn{4}{|l|}{ State } \\
\hline Arkansas & $3676(4.34)$ & 11.86 & 8.59 \\
\hline DC & 3683 (4.34) & 15.56 & 10.22 \\
\hline Hawaii & $6232(7.35)$ & 16.5 & 10.01 \\
\hline Louisiana & 8412 (9.92) & 10.64 & 6.98 \\
\hline Minnesota & $13928(16.43)$ & 10.73 & 7.81 \\
\hline Montana & 9297 (10.97) & 12.94 & 9.55 \\
\hline Nevada & 3605 (4.25) & 14.23 & 9.53 \\
\hline Vermont & $13331(15.72)$ & 14.73 & 10.90 \\
\hline Washington & $13901(16.4)$ & 14.16 & 10.22 \\
\hline Wisconsin & $8721(10.29)$ & 12.7 & 9.77 \\
\hline
\end{tabular}


covariates, including age, sex, race/ethnicity, income and education levels. Higher asthma prevalence was seen among women, those in the lower age groups, among NHW populations and those reporting lower income and education levels. Stressful living conditions was the most commonly reported dimension of ACE $(34.46 \%)$ followed by any verbal abuse $(32.62 \%)$ and parental marital discord (20.67\%; table 2). Nearly $12.29 \%$ reported any experience of sexual abuse.

Exposure to experiences of adversity was associated with higher asthma prevalence. Experiencing parental marital discord and living in stressful conditions were respectively associated with higher lifetime asthma prevalence (parental marital discord: $16.77 \%$ vs $12.2 \%$; $\mathrm{p}<0.0001$, and stressful living conditions: $17.14 \%$ vs $11.12 \%$; $\mathrm{p}<0.0001)$. Asthma prevalence was higher among those reporting an experience of verbal abuse ( $16.77 \%$ vs $11.46 \%$ : $\mathrm{p}<0.0001)$, any physical abuse $(17.7 \%$ vs $11.87 \%$ : $\mathrm{p}<0.0001)$ or any sexual abuse $(20.34 \%$ vs 12.16\%: $\mathrm{p}<0.0001$ ), compared to those with no experience of the specific adversity.

\section{ACE and asthma prevalence}

High adversity in childhood was associated with greater asthma prevalence, with evidence for a stepwise gradient (table 3). Each ACE category was seen to be positively related to asthma current and lifetime prevalence. Small differences in the asthma PRs were noted for this exploratory gradient between respondents reporting categories 2 and 3 adversity. Highest risks for asthma prevalence were seen among respondents reporting highest ACE compared to those reporting no adversity ( $\mathrm{PR}=2.03$ (95\% CI 1.94 to 2.14)). Adjusting for race/ethnicity, SES, demographic covariates and state of residence led to proportionally greater attenuations in asthma prevalence $(\sim 30 \%)$ among those who reported all dimensions of ACE (adjusted PR (APR) $=1.78$ (95\% CI 1.69 to 1.87) compared to lower categories of ACE. Similar patterns were noted for current asthma with unadjusted $\mathrm{PR}=2.23$ (95\% CI 2.09 to 2.36) reducing on covariate adjustment to $\mathrm{APR}=1.88$ ( 1.77 to 2.006$)$.

Analyses for separate ACE dimensions showed positive relationships between childhood adversity and asthma prevalence, adjusted for covariates (table 4). Respondents who reported parental marital discord showed a $37 \%$ higher prevalence ( $\mathrm{PR}=1.37,95 \%$ CI 1.32 to 1.43). Adjusted for covariates, PRs reduced by $35 \%$. For current asthma, parental discord was associated with a $40 \%$ high prevalence (APR $=1.40 \quad(95 \%$ CI 1.34 to 1.47). Respondents reporting stressful living conditions in childhood showed a $54 \%$ higher asthma prevalence ( $\mathrm{PR}=1.54,95 \%$ CI 1.49 to 1.59 ), which attenuated by $18 \%$ on covariate adjustment. Stressful living conditions were associated with a $47 \%$ higher prevalence of current asthma (APR=1.47 (95\% CI 1.41 to 1.54)). Respondents reporting verbal or physical abuse showed $38 \%$ higher

Table 2 Dimensions of childhood adversity and prevalence of asthma

\begin{tabular}{|c|c|c|c|}
\hline & $\begin{array}{l}\text { Sample distribution } \\
\text { of ACE dimensions }\end{array}$ & 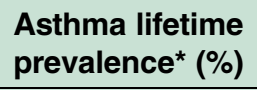 & $\begin{array}{l}\text { Asthma current } \\
\text { prevalence* }(\%)\end{array}$ \\
\hline \multicolumn{4}{|c|}{ Parental marital discord $†$} \\
\hline No & $66118(78.78)$ & $8069(12.20)$ & $5596(8.62)$ \\
\hline Yes & 17350 (20.67) & 2909 (16.77) & 2063 (12.09) \\
\hline Never married & $457(0.54)$ & 90 (19.69) & $65(14.51)$ \\
\hline Total & 83925 (100.00) & & \\
\hline \multicolumn{4}{|c|}{ Stressful living conditions $\ddagger$} \\
\hline No & $55290(65.54)$ & $6151(11.12)$ & $4209(7.77)$ \\
\hline Yes & $29076(34.46)$ & $4985(17.14)$ & $3560(12.41)$ \\
\hline Total & 84366 (100.00) & & \\
\hline \multicolumn{4}{|c|}{ Experience of verbal abuse } \\
\hline No & 55966 (67.38) & $6412(11.46)$ & $4425(8.05)$ \\
\hline Yes & 27096 (32.62) & $4543(16.77)$ & $3210(12.02)$ \\
\hline Total & $83062(100.00)$ & & \\
\hline \multicolumn{4}{|c|}{ Experiences of physical violence (on individual or parent)§ } \\
\hline No & $64880(77.22)$ & $7701(11.87)$ & $5267(8.27)$ \\
\hline Yes & $19143(22.78)$ & $3388(17.70)$ & $2469(13.10)$ \\
\hline Total & $84023(100.00)$ & & \\
\hline \multicolumn{4}{|c|}{ Experiences of sexual abuse in childhoodๆ } \\
\hline No & $73475(87.71)$ & $8936(12.16)$ & $6141(8.51)$ \\
\hline Yes & $10294(12.29)$ & $2094(20.34)$ & $1528(15.28)$ \\
\hline Total & $83769(100.00)$ & & \\
\hline \multicolumn{4}{|c|}{$\begin{array}{l}\text { *Differences were statistically significant with } p<0.0001 . \\
\text { †Marital status of parents: were they divorced/separated? } \\
\text { tLived with someone who was depressed, mentally ill, suicidal, alcoholic, illegal drug user or had served time in prison. } \\
\text { §Experienced violence in the household (verbal or physical). } \\
\text { ๆExperience of sexual abuse. } \\
\text { ACE, adverse childhood experience. }\end{array}$} \\
\hline
\end{tabular}


Table 3 Prevalence ratios from Poisson regression models for lifetime asthma by overall ACE score

\begin{tabular}{|c|c|c|c|c|c|c|c|c|}
\hline & \multicolumn{4}{|c|}{ Lifetime asthma prevalence } & \multicolumn{4}{|c|}{ Current asthma prevalence } \\
\hline & Unadjusted & $\begin{array}{l}\text { Adjusted (age, } \\
\text { sex, survey year) }\end{array}$ & $\begin{array}{l}\text { Adjusted (age, } \\
\text { sex, survey } \\
\text { year, SES) }\end{array}$ & $\begin{array}{l}\text { Adjusted (age, } \\
\text { sex, survey year, } \\
\text { SES and state) }\end{array}$ & Unadjusted & $\begin{array}{l}\text { Adjusted (age, } \\
\text { sex, survey year) }\end{array}$ & $\begin{array}{l}\text { Adjusted (age, } \\
\text { sex, survey } \\
\text { year, SES) }\end{array}$ & $\begin{array}{l}\text { Adjusted (age, } \\
\text { sex, survey year, } \\
\text { SES and state) }\end{array}$ \\
\hline $\begin{array}{l}\text { ACE Categories (Ref: } \\
\text { None) }\end{array}$ & 1.00 & 1.00 & 1.00 & 1.00 & 1.00 & 1.00 & 1.00 & 1.00 \\
\hline 1 & $1.24(1.18$ to 1.30$)$ & 1.23 (1.17 to 1.29$)$ & $1.22(1.16$ to 1.27$)$ & 1.21 (1.16 to 1.27$)$ & $1.26(1.18$ to 1.33$)$ & 1.25 (1.18 to 1.33$)$ & 1.24 (1.17 to 1.32$)$ & $1.24(1.17$ to 1.31$)$ \\
\hline 2 & 1.52 (1.44 to 1.62$)$ & $1.46(1.37$ to 1.55$)$ & 1.44 (1.35 to 1.53$)$ & $1.44(1.35$ to 1.53$)$ & 1.54 (1.43 to 1.66$)$ & 1.50 (1.39 to 1.62$)$ & 1.48 (1.37 to 1.59$)$ & 1.47 (1.37 to 1.59$)$ \\
\hline 3 & 1.54 (1.46 to 1.63$)$ & $1.52(1.44$ to 1.6$)$ & 1.46 (1.38 to 1.54$)$ & $1.46(1.38$ to 1.53$)$ & 1.62 (1.52 to 1.73$)$ & 1.63 (1.53 to 1.73$)$ & 1.54 (1.44 to 1.64$)$ & 1.54 (1.44 to 1.64$)$ \\
\hline 4 & 2.03 (1.94 to 1.14$)$ & 1.89 (1..8 to 1.99$)$ & 1.79 (1.71 to 1.89$)$ & 1.78 (1.69 to 1.87$)$ & 2.23 (2.09 to 2.36$)$ & 2.03 (1.91 to 2.16$)$ & 1.89 (1.78 to 2.02$)$ & 1.88 (1.77 to 2.006$)$ \\
\hline Female & & 1.35 (1.3 to 1.4$)$ & 1.32 (1.27 to 1.37$)$ & 1.31 (1.26 to 1.36$)$ & & 1.57 (1.49 to 1.65$)$ & 1.52 (1.46 to 1.60$)$ & $1.53(1.45$ to 1.60$)$ \\
\hline \multicolumn{9}{|l|}{ Age (in years) } \\
\hline $25-44$ & & 0.8 (0.74 to 0.87$)$ & 0.86 (0.79 to 0.93$)$ & 0.86 (0.79 to 0.93$)$ & & 0.87 (0.78 to 0.97$)$ & 0.98 (0.88 to 1.09$)$ & 0.97 (0.87 to 1.09$)$ \\
\hline $45-64$ & & 0.72 (0.67 to 0.78$)$ & 0.77 (0.71 to 0.84$)$ & 0.77 (0.71 to 0.83$)$ & & $0.83(0.75$ to 0.93$)$ & $0.93(0.84$ to 1.04$)$ & $0.92(0.83$ to 1.02$)$ \\
\hline $\begin{array}{l}65+ \\
\text { Survey year }\end{array}$ & & $0.68(0.63$ to 0.74$)$ & 0.69 (0.63 to 0.75$)$ & 0.67 (0.62 to 0.73$)$ & & $0.82(0.73$ to 0.91$)$ & 0.83 (0.74 to 0.92$)$ & 0.81 (0.73 to 0.90$)$ \\
\hline 2010 & & 1.36 (1.29 to 1.44$)$ & $1.42(1.34$ to 1.51$)$ & $1.12(1.003$ to 1.25$)$ & & 1.35 (1.26 to 1.46$)$ & 1.45 (1.35 to 1.57$)$ & $1.12(0.97$ to 1.30$)$ \\
\hline 2011 & & $1.15(1.08$ to 1.21$)$ & $1.19(1.12$ to 1.26$)$ & $1.04(0.93$ to 1.16$)$ & & 1.26 (1.18 to 1.35$)$ & 1.34 (1.25 to 1.44$)$ & $1.13(0.99$ to 1.27$)$ \\
\hline \multicolumn{9}{|c|}{ 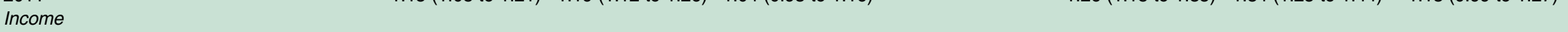 } \\
\hline US $\$ 15000-$ US $\$ 35000$ & & & 0.77 (0.72 to 0.81$)$ & 0.77 (0.73 to 0.82$)$ & & & 0.73 (0.68 to 0.78$)$ & 0.74 (0.68 to 0.79$)$ \\
\hline US $\$ 35000-U S \$ 50000$ & & & 0.67 (0.63 to 0.72$)$ & 0.67 (0.63 to 0.72$)$ & & & 0.61 (0.56 to 0.66$)$ & 0.61 (0.56 to 0.67 ) \\
\hline US\$50 000-US\$75000 & & & 0.64 (0.59 to 0.68$)$ & 0.64 (0.59 to 0.68$)$ & & & 0.57 (0.52 to 0.62$)$ & 0.57 (0.53 to 0.62$)$ \\
\hline$>$ US\$75 000 & & & 0.58 (0.54 to 0.62$)$ & 0.58 (0.54 to 0.62$)$ & & & 0.50 (0.46 to 0.54$)$ & 0.50 (0.57 to 0.55$)$ \\
\hline Do not know, refused & & & $0.72(0.67$ to 0.77$)$ & $0.72(0.67$ to 0.77$)$ & & & 0.67 (0.61 to 0.73$)$ & 0.67 (0.62 to 0.73$)$ \\
\hline \multicolumn{9}{|l|}{ Education } \\
\hline Finished high school & & & 0.81 (0.76 to 0.87$)$ & 0.81 (0.76 to 0.87$)$ & & & 0.77 (0.71 to 0.83$)$ & 0.77 (0.71 to 0.84$)$ \\
\hline Some college & & & 0.89 (0.83 to 0.95$)$ & $0.89(0.83$ to 0.95$)$ & & & $0.79(0.74$ to 0.86$)$ & $0.80(0.74$ to 0.87$)$ \\
\hline College or more & & & 0.90 (0.84 to 0.97$)$ & 0.9 (0.84 to 0.96$)$ & & & 0.80 (0.74 to 0.87$)$ & 0.79 (0.73 to 0.87$)$ \\
\hline \multicolumn{9}{|l|}{ State } \\
\hline DC & & & & $1.22(1.11$ to 1.35$)$ & & & & 1.17 (1.02 to 1.34$)$ \\
\hline Hawaii & & & & $1.3(1.19$ to 1.41$)$ & & & & 1.13 (0.99 to 1.28$)$ \\
\hline Louisiana & & & & 0.88 (0.79 to 0.97$)$ & & & & 0.80 (0.71 to 0.92$)$ \\
\hline Minnesota & & & & 0.9 (0.83 to 0.97$)$ & & & & 0.89 (0.81 to 0.97$)$ \\
\hline Montana & & & & 1.03 (0.95 to 1.12$)$ & & & & $1.006(0.87$ to 1.16$)$ \\
\hline Nevada & & & & 1.07 (0.96 to 1.18$)$ & & & & 1.19 (1.09 to 1.31$)$ \\
\hline Vermont & & & & 1.18 (1.10 to 1.27$)$ & & & & 1.09 (1.01 to 1.18$)$ \\
\hline Washington & & & & 1.15 (1.06 to 1.24$)$ & & & & $1.04(0.95$ to 1.15$)$ \\
\hline
\end{tabular}

Baseline: age category 18-24 years, male, sampled in 2009, income <US $\$ 15000$, education less than high school, in Arkansas.

Category 1: Parental marital discord+experience of a verbal abuse; Category 2: parental marital discord+experience of a verbal abuse+stressful living conditions; Category 3: parental marital

discord+experience of a verbal abuse+stressful living conditions+experience of physical abuse; Category 4: parental marital discord+experience of a verbal abuse+stressful living conditions

discord+experience of a verbal abuse+stress

$\mathrm{ACE}$, adverse childhood experience; SES, socioeconomic status. 
Table 4 Results from Poisson regression models (PRs and 95\% Cl) for lifetime asthma prevalence by independent ACE dimensions

\begin{tabular}{|c|c|c|c|c|c|c|c|c|}
\hline & \multicolumn{4}{|l|}{ Lifetime asthma } & \multicolumn{4}{|l|}{ Current asthma } \\
\hline & $\begin{array}{l}\text { Model 1: } \\
\text { Unadjusted }\end{array}$ & $\begin{array}{l}\text { Model 2: Adjusted } \\
\text { for age, sex, race, } \\
\text { survey year }\end{array}$ & $\begin{array}{l}\text { Model 3: Adjusted } \\
\text { for age, sex, race, } \\
\text { survey year, } \\
\text { income and } \\
\text { education }\end{array}$ & $\begin{array}{l}\text { Model 4: Adjusted } \\
\text { for age, sex, race, } \\
\text { survey year, } \\
\text { income and } \\
\text { education, and } \\
\text { State }\end{array}$ & $\begin{array}{l}\text { Model 1: } \\
\text { Unadjusted }\end{array}$ & $\begin{array}{l}\text { Model 2: Adjusted } \\
\text { for age, sex, race, } \\
\text { survey year }\end{array}$ & $\begin{array}{l}\text { Model 3: Adjusted } \\
\text { for age, sex, race, } \\
\text { survey year, } \\
\text { income and } \\
\text { education }\end{array}$ & $\begin{array}{l}\text { Model 4: Adjusted } \\
\text { for age, sex, race, } \\
\text { survey year, } \\
\text { income and } \\
\text { education, and } \\
\text { State }\end{array}$ \\
\hline \multicolumn{9}{|c|}{ Parental marital discord } \\
\hline No & 1.00 & 1.00 & 1.00 & 1.00 & 1.00 & 1.00 & 1.00 & 1.00 \\
\hline Yes & $1.37(1.32$ to 1.43$)$ & $1.3(1.25$ to 1.35$)$ & $1.26(1.21$ to 1.31$)$ & 1.24 (1.19 to 1.29$)$ & $1.40(1.34$ to 1.47$)$ & $1.37(1.30$ to 1.44$)$ & $1.28(1.22$ to 1.35$)$ & $1.27(1.21$ to 1.34$)$ \\
\hline Never married & $1.63(1.35$ to 1.95$)$ & 1.39 (1.14 to 1.69$)$ & 1.31 (1.08 to 1.58$)$ & 1.33 (1.09 to 1.6$)$ & $1.68(1.34$ to 2.11$)$ & 1.58 (1.26 to 1.99$)$ & 1.37 (1.09 to 1.71$)$ & 1.40 (1.12 to 1.76$)$ \\
\hline \multicolumn{9}{|c|}{ Stressful living conditions before age 18} \\
\hline No & 1.00 & 1.00 & 1.00 & 1.00 & 1.00 & 1.00 & 1.00 & 1.00 \\
\hline Yes & 1.54 (1.49 to 1.59$)$ & 1.48 ( 1 to 43 to 1.54$)$ & 1.45 (1.39 to 1.5$)$ & 1.44 (1.39 to 1.49$)$ & 1.59 (1.53 to 1.66$)$ & $1.53(1.47$ to 1.60$)$ & $1.48(1.42$ to 1.54$)$ & $1.47(1.41$ to 1.54$)$ \\
\hline \multicolumn{9}{|c|}{ Reported experience of verbal abuse before age 18} \\
\hline No & 1.00 & 1.00 & 1.00 & 1.00 & 1.00 & 1.00 & 1.00 & 1.00 \\
\hline Yes & 1.46 (1.41 to 1.52$)$ & $1.42(1.37$ to 1.47$)$ & $1.38(1.34$ to 1.43$)$ & 1.38 (1.33 to 1.43$)$ & 1.49 (1.43 to 1.56$)$ & 1.45 (1.39 to 1.52$)$ & $1.41(1.35$ to 1.47$)$ & $1.41(1.35$ to 1.47$)$ \\
\hline \multicolumn{9}{|c|}{ Reported experience of physical violence before age 18} \\
\hline No & 1.00 & 1.00 & 1.00 & 1.00 & 1.00 & 1.00 & 1.00 & 1.00 \\
\hline Yes & 1.49 (1.44 to 1.55$)$ & $1.44(1.39$ to 1.50$)$ & 1.38 (1.33 to 1.44$)$ & 1.38 (1.33 to 1.43$)$ & $1.58(1.51$ to 1.66$)$ & 1.55 (1.48 to 1.62$)$ & 1.45 (1.39 to 1.52$)$ & 1.45 (1.39 to 1.52$)$ \\
\hline \multicolumn{9}{|c|}{ Reported experience of sexual abuse before age 18} \\
\hline No & 1.00 & 1.00 & 1.00 & 1.00 & 1.00 & 1.00 & 1.00 & 1.00 \\
\hline Yes & $1.67(1.59$ to 1.74$)$ & $1.56(1.49$ to 1.63$)$ & 1.49 (1.43 to 1.56$)$ & 1.48 (1.42 to 1.55$)$ & 1.79 (1.70 to 1.89$)$ & $1.63(1.55$ to 1.72$)$ & $1.54(1.46$ to 1.63$)$ & $1.53(1.45$ to 1.62$)$ \\
\hline
\end{tabular}


Table 5 Results from Poisson regression models on combinations of adversity experiences

\begin{tabular}{|c|c|c|c|c|}
\hline & \multicolumn{2}{|l|}{ Asthma prevalence } & \multicolumn{2}{|l|}{ Current asthma } \\
\hline & $\begin{array}{l}\text { Adjusted for age, } \\
\text { sex, survey year }\end{array}$ & Fully adjusted & $\begin{array}{l}\text { Adjusted for age, } \\
\text { sex, survey year }\end{array}$ & Fully adjusted \\
\hline No adversity & 1.00 & 1.00 & 1.00 & 1.00 \\
\hline Parental discord & $1.17^{*}(1.08$ to 1.28$)$ & $1.13^{*}(1.04$ to 1.23$)$ & $1.24^{*}(1.12$ to 1.38$)$ & $1.18^{*}(1.06$ to 1.31$)$ \\
\hline Stressful living conditions & $1.31^{*}(1.23$ to 1.40$)$ & $1.31^{*}(1.23$ to 1.41$)$ & $1.35^{\star}(1.24$ to 1.46$)$ & $1.35^{\star}(1.24$ to 1.46$)$ \\
\hline Verbal abuse & $1.16^{*}(1.08$ to 1.26$)$ & $1.17^{\star}(1.08$ to 1.27$)$ & $1.15^{\star}(1.05$ to 1.27$)$ & $1.17^{*}(1.06$ to 1.28$)$ \\
\hline Physical abuse & $1.03(0.90$ to 1.18$)$ & $1.01(0.88$ to 1.15$)$ & $1.08(0.92$ to 1.28$)$ & 1.04 (0.88 to 1.23$)$ \\
\hline Sexual abuse & $1.34^{*}(1.18$ to 1.51$)$ & $1.32^{*}(1.17$ to 1.49$)$ & $1.38^{*}(1.19$ to 1.59$)$ & $1.37^{*}(1.18$ to 1.59$)$ \\
\hline $\begin{array}{l}\text { Parental discord and stressful living } \\
\text { conditions }\end{array}$ & $1.50^{*}(1.36$ to 1.67$)$ & $1.46^{\star}(1.31$ to 1.62$)$ & $1.58^{\star}(1.39$ to 1.79$)$ & $1.50^{\star}(1.32$ to 1.71$)$ \\
\hline Parental discord and Verbal abuse & $1.24^{*}(1.06$ to 1.45$)$ & $1.22^{*}(1.04$ to 1.42$)$ & $1.26^{*}(1.04$ to 1.53$)$ & $1.23^{\star}(1.01$ to 1.49$)$ \\
\hline Parental discord and physical abuse & $1.14(0.91$ to 1.44$)$ & 1.08 (0.86 to 1.37$)$ & $1.32^{*}(1.008$ to 1.72$)$ & $1.22(0.94$ to 1.60$)$ \\
\hline Parental discord and sexual abuse & $1.59^{*}(1.24$ to 2.06$)$ & $1.50^{\star}(1.17$ to 1.93$)$ & $1.55^{\star}(1.13$ to 2.13$)$ & $1.44^{*}(1.04$ to 1.97$)$ \\
\hline $\begin{array}{l}\text { Stressful living Conditions and verbal } \\
\text { abuse }\end{array}$ & $1.47^{*}(1.36$ to 1.58$)$ & $1.46^{*}(1.35$ to 1.57$)$ & $1.49^{\star}(1.36$ to 1.63$)$ & $1.47^{*}(1.35$ to 1.62$)$ \\
\hline Stressful living conditions and physical & $1.46^{\star}(1.32$ to 1.62$)$ & $1.40^{*}(1.26$ to 1.55$)$ & $1.58^{*}(1.40$ to 1.79$)$ & $1.49^{*}(1.32$ to 1.69$)$ \\
\hline $\begin{array}{l}\text { Stressful living conditions and sexual } \\
\text { abuse }\end{array}$ & $1.54^{\star}(1.35$ to 1.75$)$ & $1.50^{*}(1.32$ to 1.71$)$ & $1.64^{\star}(1.40$ to 1.92$)$ & $1.59^{\star}(1.36$ to 1.86$)$ \\
\hline Verbal and physical abuse & $1.62^{*}(1.53$ to 1.71$)$ & $1.56^{*}(1.47$ to 1.65$)$ & $1.73^{\star}(1.62$ to 1.86$)$ & $1.65^{\star}(1.54$ to 1.76$)$ \\
\hline Verbal and sexual abuse & $1.66^{*}(1.49$ to 1.83$)$ & $1.59^{*}(1.44$ to 1.77$)$ & $1.75^{\star}(1.54$ to 1.98$)$ & $1.68^{*}(1.48$ to 1.90$)$ \\
\hline Physical and sexual abuse & $2.20^{*}$ (2.07 to 2.33$)$ & $2.03^{*}(1.91$ to 2.15$)$ & $2.41^{*}(2.23$ to 2.58$)$ & $2.15^{*}$ (2.009 to 2.31$)$ \\
\hline
\end{tabular}

adjusted risks for asthma prevalence (APR $=1.38,95 \%$ CI 1.33 to 1.43$)$. Respondents reporting sexual abuse had a $67 \%$ higher asthma prevalence (PR=1.67, 95\% CI 1.59 to 1.74$)$; covariate adjustment moderately attenuated the estimated risk (APR=1.48, (95\% CI 1.42 to 1.55$))$. Respondents reporting any experience of sexual abuse were noted to have a $53 \%$ higher prevalence of current asthma (APR=1.53 (95\% CI 1.45 to 1.62$)$ ).

Additionally, combined experiences of adversity provided greater risks of asthma lifetime and current prevalence, particularly for respondents reporting physical and sexual abuse (APR=2.15 (95\% CI 2.009 to 2.31)), verbal and sexual abuse $(\mathrm{APR}=1.68(1.48$ to 1.90$))$ and verbal and physical abuse $(\mathrm{APR}=1.65$ (95\% CI 1.54 to 1.76); table 5). Among the singular dimensions of asthma, adjusted for covariates and other dimensions of adversity, stressful living conditions and experience of sexual abuse in childhood predicted the highest risks of asthma prevalence (Stressful Living Conditions: $\mathrm{APR}=1.35 \quad(95 \%$ CI 1.24 to 1.46$)$; Sexual Abuse: $\mathrm{APR}=1.37$ (95\% CI 1.18 to 1.59$))$. The risks for asthma among those reporting parental marital discord only $(\mathrm{APR}=1.24(95 \%$ CI 1.12 to 1.38$))$ and parental marital discord with verbal abuse (APR $=1.26$ (95\% CI 1.04 to 1.53)) were similar.

\section{Social determinants of adversity}

Higher rates of parental marital discord (separation or divorce) were reported by racial/ethnic minorities (NHB: $36.88 \%$, Hispanic: $28.48 \%$ vs NHW: $18.93 \%$; table 6 ). Hispanics reported higher rates of adversity seen through rates of living in stressful conditions $(38.5 \%)$ compared to
NHW $(34.6 \%)$ and NHB $(32.8 \%)$ populations. Higher rates of verbal and physical abuse were also reported by Hispanics (verbal abuse: $36.3 \%$, physical abuse: $34.24 \%$ ) compared to NHW (verbal abuse: $32.7 \%$, physical abuse: $21.4 \%$ ) and NHB (verbal abuse: $26.4 \%$, physical abuse: $26.08 \%$ ). Hispanics reported higher rates of sexual abuse $(14.26 \%)$ compared to NHB (12.1\%) and NHW $(12.05 \%)$ populations.

The lowest income and educational categories reported higher rates of adversity but a clear SES gradient could not be established (see online supplementary table S3). Respondents with less than high school education reported greater parental marital discord $(29.28 \%)$ compared to college educated respondents $(15.82 \%)$; similar rates were seen for any physical abuse $(<$ high school education: $30.48 \%$ vs college educated: $18.97 \%)$. Respondents with lowest incomes (income $<$ US\$15 000) reported higher adversity, with small differences between the remaining groups. Lowest income respondents (<US\$15000) reported higher parental marital discord $(29.27 \%)$ and stressful living conditions $(42.6 \%)$ compared to respondents with income between US $\$ 15000$ and US\$35000 (parental marital discord: $22.78 \%$, stressful living conditions: $35.52 \%$ ). Those in the lowest income group also reported higher rates of sexual abuse (19.02\%) compared to $10.77 \%$ in the highest income group.

\section{DISCUSSION}

Our study reports three major findings. First, we found a positive relationship between childhood adversity and 
Table 6 Distribution of ACE dimensions by race/ethnicity, income and education in the BRFSS

\begin{tabular}{|c|c|c|c|c|c|c|}
\hline & $\begin{array}{l}\text { Parents } \\
\text { separated or } \\
\text { divorced }\end{array}$ & $\begin{array}{l}\text { Parents } \\
\text { never } \\
\text { married }\end{array}$ & $\begin{array}{l}\text { Reported } \\
\text { stressful living } \\
\text { conditions } \\
\text { before age } 18\end{array}$ & $\begin{array}{l}\text { Reported } \\
\text { verbal abuse }\end{array}$ & $\begin{array}{l}\text { Reported } \\
\text { experience of } \\
\text { physical } \\
\text { violence before } \\
\text { age } 18\end{array}$ & $\begin{array}{l}\text { Reported } \\
\text { experience of } \\
\text { sexual abuse } \\
\text { before age } 18\end{array}$ \\
\hline \multicolumn{7}{|l|}{ Race/ethnicity } \\
\hline Non-Hispanic White & 12836 (18.93) & $182(0.27)$ & 23564 (34.61) & 21936 (32.70) & $14518(21.40)$ & 8155 (12.05) \\
\hline Non-Hispanic Black & 1918 (36.88) & $183(3.52)$ & 1735 (32.82) & $1368(26.42)$ & 1367 (26.08) & 632 (12.10) \\
\hline Hispanic & $716(28.48)$ & 25 (0.99) & 979 (38.51) & 909 (36.35) & $865(34.24)$ & 359 (14.26) \\
\hline Others & $1679(22.54)$ & $60(0.81)$ & 2517 (33.61) & $2610(35.38)$ & $2183(29.28)$ & $1029(13.84)$ \\
\hline \multicolumn{7}{|l|}{ Education } \\
\hline Less than High school & $1627(29.28)$ & $74(1.33)$ & $2134(37.88)$ & $1706(30.95)$ & $1703(30.48)$ & 796 (14.26) \\
\hline Finished high school & 5327 (23.00) & $155(0.67)$ & 7925 (34.00) & $6979(30.46)$ & 5512 (23.79) & $2586(11.20)$ \\
\hline Some college & 5258 (22.79) & $135(0.59)$ & $8510(36.71)$ & 8070 (35.33) & 5797 (25.09) & 3225 (14.01) \\
\hline College or more & 4937 (15.82) & $86(0.28)$ & 10226 (32.69) & 10068 (32.60) & 5921 (18.97) & $3568(11.46)$ \\
\hline \multicolumn{7}{|l|}{ Income } \\
\hline$<$ US\$15000 & 2011 (29.27) & $88(1.28)$ & $2960(42.60)$ & 2608 (38.27) & $2256(32.71)$ & 1306 (19.02) \\
\hline US\$15 000-35000 & $4972(22.78)$ & $157(0.72)$ & 7799 (35.52) & 7067 (32.68) & $5511(25.21)$ & $2927(13.43)$ \\
\hline US\$35 000-US\$50 000 & 2299 (19.66) & $52(0.44)$ & 4009 (34.16) & 3733 (32.29) & 2677 (22.88) & 1369 (11.73) \\
\hline US\$50 000-US\$75 000 & 2405 (19.17) & $43(0.34)$ & 4377 (34.80) & 4203 (33.77) & 2764 (22.00) & $1466(11.71)$ \\
\hline$>$ US\$75 000 & $3686(17.90)$ & $48(0.23)$ & 7005 (33.93) & $6805(33.31)$ & $4013(19.48)$ & $2213(10.77)$ \\
\hline $\begin{array}{l}\text { Refused, missing or do } \\
\text { not know }\end{array}$ & $1776(18.78)$ & $62(0.66)$ & $2645(27.72)$ & 2407 (25.97) & $1712(18.10)$ & $894(9.48)$ \\
\hline
\end{tabular}

asthma prevalence that persisted after adjusting for covariates. Second, we observed increasing asthma by categories of adversity, which has not been investigated in previous research. Studies on childhood adversity need to investigate the scope and meaning of this observed gradient, including whether these relationships hold for other health outcomes. Third, separate dimensions of ACE were associated with asthma prevalence, with the strength of the relationship varying by exposure.

The linkages between childhood adversity and asthma may be explained by the physiological evidence on the role of sociobiological and neurobiological mechanisms from stress and adversity. These mechanisms go on to impact immune and inflammatory responses, muscular and nervous system mechanisms, and hormonal and obesity-related mechanisms, all of which relate to asthma. $^{12-15}$ Studies on asthma prevalence have also attributed some of the disease burden to environmental risk factors, including poor control of pollutants (toxins, dust and mites) in the household. ${ }^{36-42}$ There is also some evidence on clustering or co-occurrence of risks of disadvantages (socioeconomic, adversity and environmental risks) within households. ${ }^{14} 364344$ Studies have, in the past, examined the relationships between stress during pregnancy and postpregnancy and asthma among children. ${ }^{9}$ The scope for connecting pregnancy and early life exposures to childhood adversity was not available in the BRFSS surveys, and needs to be investigated in future analyses.

An aspect needing more examination in studies of adversity pertains to the interrelatedness of dimensions. ${ }^{33}$
Previous assessments of adversity have shown high degrees of interconnectedness, with the presence of one dimension of adversity increasing the probability of additional ACE exposures (adjusted odds between 2 and 17.7 times, median 2.8). ${ }^{33}$ In our study, $12 \%$ of the respondents reported having experienced all dimensions of adversity and $23 \%$ reported the lowest category of adversity-experiencing parental discord and verbal abuse (see online supplementary table $\mathrm{S} 1$ ). This co-occurrence of multiple ACE dimensions also varied by gender. In our study, the reported experience of the overall ACE score was higher among women compared to men $(15.08 \%$ vs $6.5 \%)$, but when sexual abuse was excluded, men (16.2\%) reported higher ACE compared to women $(12.44 \%)$. Lower levels of adversity did not show gender differences.

In addition to understanding the level of co-occurrence of experiences of adversity, examining the role of combinations of adverse experiences may potentially be another area for research in the future. Research needs to examine the health effects of combinations of adversity, and whether certain experiences singularly or in consonance with others have greater impacts than others. Our additional analyses (table 5) showed that experiencing multiple types of abuse (verbal, physical and sexual) can magnify risks for asthma, beyond the experience of a singular adversity dimension.

We adjusted for race/ethnicity and SES in the relationships between childhood adversity and asthma prevalence. Several studies have shown the racial/ethnic and SES patterning of asthma prevalence rates in the 
USA. $^{44-48}$ A review on maltreatment highlighted the potential role of parental poverty and low educational achievement. ${ }^{49}$ Since we did not have data on parental SES or SES of the respondents during childhood, we adjusted for own SES as a proxy for the same. Those in the lowest income and education groups reported higher rates on all dimensions of ACE, but since this information does not necessarily correspond to childhood SES, the patterning of the adversity-asthma relationship by SES remains unclear. Associations of smoking with adversity and asthma may also be another aspect of relevance, ${ }^{27} 50$ with smoking either being potentially driven by experiences of adversity, or as an independent predictor of asthma. Adjusting for smoking in the analyses (see online supplementary table S4) would only be relevant if the attempt was to disentangle the behavioural determinants from neuroendocrinal mechanisms.

\section{Limitations}

Findings from this study need interpretation in light of certain limitations. While data from the BRFSS surveys provide tremendous value in surveying major health conditions and behaviours in the USA, these surveys, based on self-reported data and recall, may be prone to several limitations. First, adversity measured through ACE in the BRFSS surveys was self-reported and based on recall. Information was unavailable in the surveys on the exact timing or duration of the exposure. Social desirability bias, limited duration of questioning and the sensitivity of ACE questions may lead to underestimation of the true burden of ACE in the population..$^{51} \mathrm{~A}$ study on self-reporting of abuse in surveys has shown that self-reported accounts can be underestimates or overestimates. ${ }^{52}$ Second, our analysis is based on childhood adversity data available from a subsample of the BRFSS from 10 states over 3 years. No information was available on why these states were chosen. Third, the data were crosssectional, and hence this analysis only examined associations and does not present a causal argument. Information on age at asthma diagnosis was available based on recall for a subset, but this could not be related to the timing of the experience of adversity. Fourth, BRFSS asthma questions have not been systematically examined for reliability and validity, and diagnostic assessments are needed to compare the strengths and limitations of self-reported physician-diagnosed asthma prevalence in population-level studies. Even as the questions in the surveys on asthma have asked respondents about physician diagnoses, careful assessment is needed on the validity of these questions. Finally, BRFSS did not provide data on parental SES. A key element for future research in the area linking adversity to asthma will pertain to the SES linkages, which may also be relevant from an intervention point of view.

\section{Conclusion}

We found positive relationships between retrospectively reported childhood adversity and current and lifetime asthma prevalence. The framework for asthma prevention needs to recognise the importance of childhood adversity as an important risk factor. Greater investigation is needed to understand the specific time periods in which this experience may have an enhanced effect on the risks for asthma, along with linking it to early life exposures.

Contributors NB, MMG, IK and SVS jointly conceptualised the study. NB led the data analysis, interpretation and writing of the manuscript. MMG, IK and SVS contributed to the interpretation and writing of the manuscript and provided overall supervision.

Funding This research received no specific grant from any funding agency in the public, commercial or not-for-profit sectors.

Competing interests At the time of research, NB was a doctoral student at the Harvard School of Public Health and received the Presidential Scholarship at Harvard University (2009-2013). SVS is supported by the Robert Wood Johnson Investigator Award in Health Policy Research; he was also partially supported by the National Institutes of Health Career Development Award (NHLBI K25 HL081275) when the study was conducted.

Provenance and peer review Not commissioned; externally peer reviewed.

Open Access This is an Open Access article distributed in accordance with the Creative Commons Attribution Non Commercial (CC BY-NC 3.0) license, which permits others to distribute, remix, adapt, build upon this work noncommercially, and license their derivative works on different terms, provided the original work is properly cited and the use is non-commercial. See: http:// creativecommons.org/licenses/by-nc/3.0/

\section{REFERENCES}

1. Wright RJ. Epidemiology of stress and asthma: from constricting communities and fragile families to epigenetics. Immunol Allergy Clin North Am 2011;31:19-39.

2. Wright RJ. Perinatal stress and early life programming of lung structure and function. Biol Psychol 2010;84:46-56.

3. Wright RJ, Brunst KJ. Programming of respiratory health in childhood: influence of outdoor air pollution. Curr Opin Pediatr 2013;25:232-9.

4. Wright RJ, Enlow MB. Maternal stress and perinatal programming in the expression of atopy. Expert Rev Clin Immunol 2008;4:535-8.

5. Milam J, McConnell R, Yao L, et al. Parental stress and childhood wheeze in a prospective cohort study. J Asthma 2008;45:319-23.

6. Shankardass K, McConnell R, Jerrett M, et al. Parental stress increases the effect of traffic-related air pollution on childhood asthma incidence. Proc Natl Acad Sci USA 2009;106:12406-11.

7. Wright RJ, Cohen S, Carey V, et al. Parental stress as a predictor of wheezing in infancy: a prospective birth-cohort study. Am J Respir Crit Care Med 2002;165:358-65.

8. Chun TH, Weitzen SH, Fritz GK. The asthma/mental health nexus in a population-based sample of the United States. Chest 2008;134:1176-82.

9. Cookson H, Granell R, Joinson C, et al. Mothers' anxiety during pregnancy is associated with asthma in their children. J Allergy Clin Immunol 2009;123:847-53.e11.

10. Jackson JS, Knight KM, Rafferty JA. Race and unhealthy behaviors: chronic stress, the HPA axis, and physical and mental health disparities over the life course. Am J Public Health 2010;100:933-9.

11. Weidner G, Kohlmann CW, Dotzauer E, et al. The effects of academic stress on health behaviors in young adults. Anxiety Stress Coping 1996;9:123-33.

12. O'Connor TM, O'Halloran DJ, Shanahan F. The stress response and the hypothalamic-pituitary-adrenal axis: from molecule to melancholia. QJM 2000;93:323-33.

13. Rietveld S, Everaerd W, Creer TL. Stress-induced asthma: a review of research and potential mechanisms. Clin Exp Allergy 2000;30:1058-66.

14. Wright RJ, Rodriguez M, Cohen S. Review of psychosocial stress and asthma: an integrated biopsychosocial approach. Thorax 1998;53:1066-74.

15. Lugogo NL, Bappanad D, Kraft M. Obesity, metabolic dysregulation and oxidative stress in asthma. Biochim Biophys Acta 2011;1810:1120-6. 
16. Sismanopoulos N, Delivanis DA, Mavrommati D, et al. Do mast cells link obesity and asthma? Allergy 2013;68:8-15.

17. Anda RF, Butchart A, Felitti VJ, et al. Building a framework for global surveillance of the public health implications of adverse childhood experiences. Am J Prev Med 2010;39:93-8.

18. Anda RF, Brown DW, Dube SR, et al. Adverse childhood experiences and chronic obstructive pulmonary disease in adults. Am J Prev Med 2008;34:396-403.

19. Anda RF, Brown DW, Felitti VJ, et al. Adverse childhood experiences and prescribed psychotropic medications in adults. Am J Prev Med 2007;32:389-94.

20. Chapman DP, Liu Y, Presley-Cantrell LR, et al. Adverse childhood experiences and frequent insufficient sleep in 5 U.S. States, 2009: a retrospective cohort study. BMC Public Health 2013;13:3.

21. Dube SR, Williamson DF, Thompson T, et al. Assessing the reliability of retrospective reports of adverse childhood experiences among adult $\mathrm{HMO}$ members attending a primary care clinic. Child Abuse Neglect 2004;28:729-37.

22. Dube SR, Miller JW, Brown DW, et al. Adverse childhood experiences and the association with ever using alcohol and initiating alcohol use during adolescence. J Adolesc Health 2006;38:444.e1-10.

23. Felitti VJ, Anda RF, Nordenberg D, et al. Relationship of childhood abuse and household dysfunction to many of the leading causes of death in adults: the adverse childhood experiences (ACE) study. Am J Prev Med 1998;14:245-58.

24. Foege WH. Adverse childhood experiences: a public health perspective. (Editorial). Am J Prev Med 1998;14:354-5.

25. Hillis SD, Anda RF, Dube SR, et al. The association between adverse childhood experiences and adolescent pregnancy, long-term psychosocial consequences, and fetal death. Pediatrics 2004;113:320-7.

26. Strine TW, Dube SR, Edwards VJ, et al. Associations between adverse childhood experiences, psychological distress, and adult alcohol problems. Am J Health Behav 2012;36:408-23.

27. Strine TW, Edwards VJ, Dube SR, et al. The mediating sex-specific effect of psychological distress on the relationship between adverse childhood experiences and current smoking among adults. Subst Abuse Treat Prev Policy 2012;7:30.

28. Coogan PF, Wise LA, O'Connor GT, et al. Abuse during childhood and adolescence and risk of adult-onset asthma in African-American women. J Allergy Clin Immunol 2013;131:1058-63.

29. Scott KM, Smith DA, Ellis PM. A population study of childhood maltreatment and asthma diagnosis: differential associations between child protection database versus retrospective self-reported data. Psychosom Med 2012;74:817-23.

30. Hyland ME, Alkhalaf AM, Whalley B. Beating and insulting children as a risk for adult cancer, cardiac disease and asthma. J Behav Med 2013;36:632-40.

31. Centers for Disease Control and Prevention (CDC). Behavioral risk factor surveillance system survey data. Atlanta, Georgia: U.S. Department of Health and Human Services, Centers for Disease Control and Prevention, 2009-2011.

32. Toren K, Brisman J, Jarvholm B. Asthma and asthma-like symptoms in adults assessed by questionnaires: a literature review. Chest 1993;104:600-8.

33. Dong M, Anda RF, Felitti VJ, et al. The interrelatedness of multiple forms of childhood abuse, neglect and household dysfunction. Child Abuse Negl 2004;28:771-84.
34. Barros AJD, Hirakata VN. Alternatives for logistic regression in cross-sectional studies: an empirical comparison of models that directly estimate the prevalence ratio. BMC Med Res Methodol 2003;3:21.

35. Coutinho LM, Scazufca M, Menezes PR. (2008) Methods for estimating prevalence ratios in cross-sectional studies. Rev Saude Publica 2008;42:992-8.

36. Eggleston PA. The environment and asthma in US inner cities. Chest 2007:132(Suppl 5):782S-8S.

37. Landrigan PJ, Schechter CB, Lipton JM, et al. Environmental pollutants and disease in American children: estimates of morbidity, mortality, and costs for lead poisoning, asthma, cancer, and developmental disabilities. Environ Health Perspect 2002;110:721-8.

38. Landrigan PJ. Environmental hazards for children in USA. Int $J$ Occup Med Environ Health 1998;11:189-94. Review

39. Mendell MJ. Indoor residential chemical emissions as risk factors for respiratory and allergic effects in children: a review. Indoor Air 2007;17:259-77.

40. Nachman KE, Parker JD. Exposures to fine particulate air pollution and respiratory outcomes in adults using two national datasets: a cross-sectional study. Environ Health 2012;11:25

41. Office of the Surgeon General (US). Report of the Surgeon General's Workshop on Healthy Indoor Environment. January 1213, 2005, National Institutes of Health, Bethesda, MD. Rockville (MD): Office of the Surgeon General (US); 2005. Introduction.

42. Wong GW, von Mutius E, Douwes J, et al. Environmental determinants associated with the development of asthma in childhood. Int J Tuberc Lung Dis 2006;10:242-51.

43. Sandel M, Wright RJ. When home is where the stress is: expanding the dimensions of housing that influence asthma morbidity. Arch Dis Child 2006;91:942-8.

44. Williams DR, Sternthal M, Wright RJ. Social determinants: taking the social context of asthma seriously. Pediatrics 2009;123: S174.

45. Boudreaux ED, Emond SD, Clark S, et al. Acute asthma among adults presenting to the emergency department: the role of race/ ethnicity and socioeconomic status. Chest 2003;124:803-12.

46. Chandra D, Clark S, Camargo CA Jr. Race/ethnicity differences in the inpatient management of acute asthma in the United States. Chest 2009;135:1527-34.

47. Payne-Sturges D, Gee SC. National environmental health measures for minority and low-income populations: tracking social disparities in environmental health. Environ Res 2006;102:154-71.

48. Subramanian SV, Jun HJ, Kawachi I, et al. Contribution of race/ ethnicity and country of origin to variations in lifetime reported asthma: evidence for a nativity advantage. Am J Public Health 2009;99:690-7.

49. Gilbert R, Widom CS, Browne K, et al. Burden and consequences of Child Maltreatment in high-income countries. Child Maltreatment 1. Lancet 2009;373:68-81.

50. Vander Weg MW. Adverse childhood experiences and cigarette smoking: the 2009 Arkansas and Louisiana Behavioral Risk Factor Surveillance Systems. Nicotine Tob Res 2011;13:616-22.

51. Edwards VJ, Anda RF, Nordenberg DF, et al. Bias assessment for child abuse survey: factors affecting probability of response to a survey about child abuse. Child Abuse Negl 2001;25:307-12.

52. Haugaard JJ, Emery RE. Methodological issues in child sexual abuse research. Child Abuse Negl 1989;13:89-100. 